\title{
Lean body mass wasting and toxicity in early breast cancer patients receiving anthracyclines
}

\author{
Federica Mazzuca ${ }^{1,2}$, Concetta Elisa Onesti ${ }^{1,3}$, Michela Roberto ${ }^{1,2}$, Marco Di \\ Girolamo $^{4}$, Andrea Botticelli ${ }^{1}$, Paola Begini ${ }^{5}$, Lidia Strigari ${ }^{6}$, Paolo Marchetti ${ }^{1,2}$ and \\ Maurizio Muscaritoli \\ ${ }^{1}$ Department of Clinical and Molecular Medicine, "Sapienza" University of Rome, Rome, Italy \\ 2 Department of Medical Oncology, Sant'Andrea Hospital, Rome, Italy \\ ${ }^{3}$ Department of Medical Oncology, University Hospital ( $\mathrm{CHU}$ ) and University of Liège, Liège, Belgium \\ ${ }^{4}$ Department of Radiology, Sant'Andrea Hospital, Rome, Italy \\ ${ }^{5}$ Department of Gastroenterology, Sant'Andrea Hospital, Rome, Italy \\ ${ }^{6}$ Laboratory of Medical Physics and Expert Systems, Regina Elena National Cancer Institute, Rome, Italy \\ ${ }^{7}$ Department of Clinical Medicine, Sapienza University of Rome, Rome, Italy \\ Correspondence to: Concetta Elisa Onesti, email: elisaonesti@gmail.com \\ Keywords: breast cancer; sarcopenia; lean body mass; anthracyclines toxicity; adjuvant chemotherapy
}

Received: February 12, $2018 \quad$ Accepted: April 28, $2018 \quad$ Published: May 22, 2018

Copyright: Mazzuca et al. This is an open-access article distributed under the terms of the Creative Commons Attribution License 3.0 (CC BY 3.0), which permits unrestricted use, distribution, and reproduction in any medium, provided the original author and source are credited.

\section{ABSTRACT}

Background: Sarcopenia refers to the reduction of both volume and number of skeletal muscle fibers. Lean body mass loss is associated with survival, quality of life and tolerance to treatment in cancer patients. The aim of our study is to analyse the association between toxicities and sarcopenia in early breast cancer patients receiving adjuvant treatment.

Materials and Methods: Breast cancer patients who have received anthracyclinebased adjuvant treatment were retrospectively enrolled. CT scan images performed before, during and after adjuvant chemotherapy were used to evaluate lean body mass at third lumbar vertebra level with the software Slice Omatic V 5.0.

Results: 21 stage I-III breast cancer patients were enrolled. According to the skeletal muscle index at third lumbar vertebra cut-off $\leq 38.5 \mathrm{~cm}^{2} / \mathrm{m}^{2}, 8$ patients $(38.1 \%)$ were classified as sarcopenic before starting treatment, while 10 patients $(47.6 \%)$ were sarcopenic at the end of treatment. A lower baseline L3 skeletal muscle index is associated with G3-4 vs G0-2 toxicities $\left(33.4 \mathrm{~cm}^{2} / \mathrm{m}^{2}(31.1-39.9)\right.$ vs 40.5 $\left.\mathrm{cm}^{2} / \mathrm{m}^{2}(33.4-52.0), p=0.028\right)$. Similarly skeletal muscle cross sectional area was significantly lower in patients with G3-4 toxicities $\left(86.7 \mathrm{~cm}^{2}(82.6-104.7)\right.$ vs 109.0 $\left.\mathrm{cm}^{2}(83.3-143.9), p=0.017\right)$. L3 skeletal muscle index is an independent predictor of severe toxicity ( $p=0.0282$ ) in multivariate analysis.

Conclusion: Lean body mass loss is associated with higher grade of toxicity in early breast cancer patients receiving adjuvant chemotherapy.

\section{INTRODUCTION}

Sarcopenia, historically referred to the age-related reduction of both volume and number of muscle fibers. It leads to a functional capacity impairment with decreased strength, metabolic rate and aerobic capacity $[1,2]$.
Sarcopenia shows a multifactorial origin including disuse, endocrine function alterations, chronic diseases, inflammation and nutritional deficiencies [3]. Contrary to cachexia, sarcopenia may occur without a concomitant loss of fat mass and with a various percentage of lean body mass reduction. 
Lean body mass (LBM) is the predominant source of organism proteins which are essentials for any cellular process. Moreover, a loss of LBM and an excessive protein catabolism, as it happens in cancer patients, may lead to a decline in immune activity with increased adverse clinical outcomes [4]. Protein synthesis dysregulation may be responsible for sarcopenia. Indeed, an inadequate response to anabolic stimuli or the upregulation of proteolysis in cancer are the principle causes of muscles loss [4]. In several studies, it has been showed that a lower LBM is associated with decreased survival, quality of life and tolerance to treatment [5]. The study of both fat and LBM at the level of the third lumbar vertebra (L3), performed by dual-energy X-ray absorptiometry (DXA) and/or computed tomography (CT) scan, appears to be strongly predictive of the entire body composition [6-10]. Indeed, CT scan provide details on each inspected muscle, adipose tissue and organs, representing an objective and reproducible technique for sarcopenia evaluation as well as cancer stage assessment [7].

The exact prevalence of sarcopenia is currently unknown, due to the variety of definitions proposed, the various techniques used to detect it and the different frequencies described in several diseases [11-13]. However, a careful estimation of sarcopenia and changes in body composition could represent an important way to prevent chemotherapy toxicity and to improve quality of life and survival of cancer patients.

In this retrospective analysis, we studied the association between sarcopenia and toxicity in early breast cancer patients receiving adjuvant treatment.

\section{RESULTS}

Twenty-one stage I-III breast cancer patients who have received anthracycline-based adjuvant treatment at the Department of Medical Oncology, Sant'Andrea Hospital of Rome between February 2013 and April 2014 were retrospectively enrolled. The median age was 54 years (range: 39-72 years). Tumor histology, HER-2 and hormonal status as well as more detailed information about surgery and chemotherapy are shown in Table 1. The median body composition parameters, i.e Body Mass Index (BMI), Body Surface Area (BSA), L3 Skeletal Muscle Index (L3 SMI) and Skeletal Muscle Cross Sectional Area (CSA) at baseline and after 4 cycles of chemotherapy are reported in Table 2. Using the cut off $\leq 38.5 \mathrm{~cm}^{2} / \mathrm{m}^{2}$ for L3 SMI to define sarcopenia, 8 patients $(38.1 \%)$ were sarcopenic before starting treatment and 10 patients $(47.6 \%)$ after 4 cycles of chemotherapy, with a $9.5 \%$ increase in frequency during treatment [11]. Only 2 patients $(9.5 \%)$ were obese (BMI 31.2 and 33.7 respectively), but not sarcopenic. A proportion of $33.3 \%$ of the patients were overweight, $14.2 \%$ of witch sarcopenic according to $\leq 38.5 \mathrm{~cm}^{2} / \mathrm{m}^{2}$ cut-off.
Overall, we observed G3-4 toxicity in 19\% of the cases, mainly neutropenia $(9.5 \%)$, vomit $(4.8 \%)$, diarrhea $(4.8 \%)$, mucositis $(4.8 \%)$ and abdominal pain $(4.8 \%)$, as showed in Table 3.

The baseline value of L3 SMI has been shown to be significantly lower in patients with G3-4 toxicities compared to patients with $\mathrm{G} 0-2$ toxicities $\left(33.4 \mathrm{~cm}^{2} / \mathrm{m}^{2}\right.$ (31.1-39.9) vs $40.5 \mathrm{~cm}^{2} / \mathrm{m}^{2}$ (33.4-52.0) respectively, $p=0.028)$. Moreover, also the skeletal muscle CSA was significantly lower in G3-4 compared to patients with G0-2 toxicities $\left(86.7 \mathrm{~cm}^{2}(82.6-104.7)\right.$ vs $109.0 \mathrm{~cm}^{2}(83.3-$ 143.9) respectively, $p=0.017)$. Meanwhile, BSA and BMI values were not associated with toxicities (Table 4 and Figure 1). A lower value of both L3 SMI (Figure 2, $p$-value $<0.0001$ ) and skeletal muscle CSA (Figure 3, $p$-value $<0.0001)$ has been showed to be significantly correlated with G3-4 toxicity also during (Time 1 in Figures 2 and 3) and after 4 cycles (Time 2 in Figures 2 and 3 ) of chemotherapy.

Finally, a multivariate analysis adjusted for basal BMI, BSA, L3 SMI and CSA revealed that L3 SMI was an independent predictor of severe toxicity $(p=0.0282)$.

\section{DISCUSSION}

Sarcopenia is a common condition in cancer patients, due to altered protein catabolism [4]. Different instrumental techniques have been used to study body composition [6-10]. However, the evaluation of adipose tissue and LBM at the level of the L3 vertebra, performed by DXA and/or CT scan, appears to be the best choice $[11,13]$.

The European Working Group on sarcopenia recommends to evaluuate the presence of both low muscle mass and low muscle function (strength or performance) to determine sarcopenia [14]. However, in our study we analysed only the loss of muscle mass. In fact, being the study retrospective, it was not possible to collect informations about muscle function.

Based on the hypothesis that body composition is relevant in drugs' distribution and activity, we studied the association between sarcopenia and toxicities in breast cancer patients receiving adjuvant epirubicin-based treatment.

Several studies showed that the decrease of LBM is associated with higher chemotherapy toxicities, as well as a worse outcome in various cancer type [5, 15-40]. Moreover, a muscle wasting without adipose tissue and body weight reduction was observed during anticancer treatment with both chemotherapy and target therapy $[25,41]$. Focusing on studies conducted on breast cancer, Prado and colleagues published a study performed on 55 metastatic patients treated with capecitabine, evaluating muscle mass by CT scans at L3 vertebra level. About $25 \%$ of patients were identified as sarcopenic and $50 \%$ of them showed grade 2 or greater toxicities. Only $20 \%$ of non- 


\begin{tabular}{|c|c|c|}
\hline & Number of patients & $\%$ \\
\hline $\begin{array}{l}\text { Age (years) } \\
\text { Median } 54 \text { (39-72) }\end{array}$ & & \\
\hline $\begin{array}{l}\text { Histology } \\
\text { Ductal } \\
\text { Lobular } \\
\text { Undifferentiated }\end{array}$ & $\begin{array}{c}18 \\
2 \\
1\end{array}$ & $\begin{array}{c}85.7 \\
9.5 \\
4.7\end{array}$ \\
\hline $\begin{array}{l}\text { Stage } \\
\text { IA } \\
\text { IIA } \\
\text { IIB } \\
\text { IIIA }\end{array}$ & $\begin{array}{l}7 \\
5 \\
6 \\
3\end{array}$ & $\begin{array}{l}33.3 \\
23.8 \\
28.6 \\
14.3\end{array}$ \\
\hline $\begin{array}{l}\text { ER } \\
\text { Positive } \\
\text { negative }\end{array}$ & $\begin{array}{c}17 \\
4\end{array}$ & $\begin{array}{l}81 \\
19\end{array}$ \\
\hline $\begin{array}{l}\text { PgR } \\
\text { Positive } \\
\text { Negative }\end{array}$ & $\begin{array}{c}16 \\
5\end{array}$ & $\begin{array}{l}76.2 \\
23.8\end{array}$ \\
\hline $\begin{array}{l}\text { HER-2 } \\
\text { Amplified } \\
\text { Not amplified }\end{array}$ & $\begin{array}{c}9 \\
12\end{array}$ & $\begin{array}{l}42.9 \\
57.1\end{array}$ \\
\hline $\begin{array}{l}\text { Surgery } \\
\text { Mastectomy } \\
\text { Quadrantectomy }\end{array}$ & $\begin{array}{c}9 \\
12\end{array}$ & $\begin{array}{l}42.9 \\
57.1\end{array}$ \\
\hline $\begin{array}{l}\text { Chemotherapy } \\
\text { FEC } \\
\text { ET } \\
\text { EC/AC }{ }^{\text {à }} \text { Ptx/Txt + Trastuzumab } \\
\text { EC }{ }^{\text {à }} \text { Ptx/Txt }\end{array}$ & $\begin{array}{l}5 \\
2 \\
9 \\
5\end{array}$ & $\begin{array}{r}23.8 \\
9.5 \\
42.9 \\
23.8\end{array}$ \\
\hline
\end{tabular}

Abbreviations: FEC: 5-fluorouracil-Epirubicin-Cyclophosphamide; ET: Epirubicin-Docetaxel; EC: EpirubicinCyclophosphamide; AC: Adraimicin-Cyclophosphamide; Ptx: Paclitaxel; Txt: Docetaxel.

Table 2: BMI, BSA and lean body mass index for the 21 enrolled patients before and after treatment

\begin{tabular}{lcccc}
\hline & \multicolumn{2}{c}{ Before treatment (T0) } & \multicolumn{2}{c}{ After treatment (T2) } \\
\cline { 2 - 5 } & Median & Range & Median & Range \\
\hline BMI $\left(\mathbf{k g} / \mathbf{c m}^{2}\right)$ & 23.6 & $18.0-33.7$ & 23.2 & $17.2-33.7$ \\
BSA $\left(\mathbf{m}^{2}\right)$ & 1.7 & $1.4-1.9$ & 1.7 & $3-2.1$ \\
L3 SMI $\left(\mathbf{c m}^{2} / \mathbf{m}^{2}\right)$ & 39.2 & $31.6-52.9$ & 39.2 & $31.6-52.9$ \\
skeletal muscle cross-sectional area $\left(\mathbf{c m}^{2}\right)$ & 103.3 & $82.6-143.9$ & 84.5 & 60 \\
Weigth $(\mathbf{K g})$ & 63.5 & $46.0-82.0$ & 135.5 \\
Height $(\mathbf{c m})$ & 161 & $150-175$ & 161 & $150-175$ \\
\hline
\end{tabular}

sarcopenic patients had severe toxicities. They observed also a shorter time to progression (TTP) in sarcopenic patients [33]. Prado and colleagues conducted also a study on 24 breast cancer patients receiving adjuvant treatment, observing a higher LBM in patients without toxicity ( $p$ 0.002) and an association between epirubicin cleareance and LBM ( $p$ 0.041) [34]. Recently, Shachar and colleagues showed a significant association between sarcopenia and toxicities in metastatic breast cancer patients treated with taxanes (57\% vs $18 \%$ of G3-4 toxicity in sarcopenic and non-sarcopenic group respectively, $p$ 0.02) and in early breast cancer receiving anthracyclines and taxanes-based chemotherapy (G3-4 toxicity relative risk $(\mathrm{RR})=1.29$ for low skeletal muscle index (SMI), $p$ 0.002; $\mathrm{RR}=1.09$ for low skeletal muscle gauge (SMG), $p$ 0.01) $[35,36]$. Rier and colleagues observed an association between 
Table 3: Toxicities reported during treatment for the 21 enrolled patients

\begin{tabular}{|c|c|c|c|c|}
\hline & \multicolumn{2}{|c|}{ G1-2 toxicity } & \multicolumn{2}{|c|}{ G3-4 toxicity } \\
\hline & $N$ & $\%$ & $N$ & $\%$ \\
\hline Neutropenia & 6 & 28.6 & 2 & 9.5 \\
\hline Anemia & 11 & 52.4 & 0 & 0 \\
\hline Nausea & 16 & 76.2 & 0 & 0 \\
\hline Vomit & 7 & 33.3 & 1 & 4.8 \\
\hline Diarrhea & 6 & 28.6 & 1 & 4.8 \\
\hline Constipation & 3 & 14.3 & 0 & 0 \\
\hline Dysgeusia & 9 & 42.9 & 0 & 0 \\
\hline Mucositis & 5 & 23.8 & 1 & 4.8 \\
\hline Abdominal pain & 2 & 9.5 & 1 & 4.8 \\
\hline Neurotoxicity & 10 & 47.6 & 0 & 0 \\
\hline HFS & 15 & 71.4 & 0 & 0 \\
\hline Cutaneous & 4 & 19.0 & 0 & 0 \\
\hline Asthenia & 17 & 81.0 & 0 & 0 \\
\hline Alopecia & 21 & 100 & 0 & 0 \\
\hline Insomnia & 5 & 23.8 & 0 & 0 \\
\hline Depression & 2 & 9.5 & 0 & 0 \\
\hline Ocular & 1 & 4.8 & 0 & 0 \\
\hline Fever & 1 & 4.8 & 0 & 0 \\
\hline
\end{tabular}

Table 4: Basal BMI, BSA, L3 index and skeletal muscle cross-sectional area according to absent/mild and severe CTC toxicity

\begin{tabular}{lccc}
\hline & Absent/mild toxicity (i.e. $\leq \mathbf{G 2})$ & Sever toxicity $(\geq \mathbf{G 3})$ & $\boldsymbol{p}$-value \\
\hline BMI $\left(\mathbf{k g} / \mathbf{c m}^{2}\right)$ & $26.4($ range: $18-33.7)$ & 22.2 (range: $18.9-24.8)$ & 0.12 \\
BSA $\left(\mathbf{m}^{2}\right)$ & $1.7($ range: $1.4-1.9)$ & $1.5($ range: $1.4-1.7)$ & 0.09 \\
L3 SMI $\left(\mathbf{c m}^{2} / \mathbf{m}^{2}\right)$ & $40.5($ range: $33.4-52.0)$ & $33.4($ range: $31.1-39.9)$ & 0.028 \\
$\begin{array}{l}\text { skeletal muscle } \\
\text { cross-sectional area }\left(\mathbf{c m}^{2}\right)\end{array}$ & $109.0($ range: $83.3-143.9)$ & $86.7($ range: $82.6-104.7)$ & 0.017 \\
\hline
\end{tabular}

low muscle attenuation (LMA) and shorter OS in 166 metastatic breast cancers receiving first line chemotherapy [37]. Deluche and colleagues identified an association of L3 SMI with both DFS and OS in 119 breast cancer patients [38]. Finally, Villaseñor and colleagues observed that sarcopenia is associated with an increased risk of overall mortality in a cohort of 471 stage I-IIIA breast cancer patients [40].

Currently, the adjustment of anticancer drugs doses is based on physical parameters (weight, height and BSA), not considering changes in the relationship between fat and lean mass, typical of natural history of cancer patients [42]. Nevertheless, there are growing evidences that LBM can be a better parameter for the evaluation of chemotherapy doses. For instance, Gusella and colleagues demonstrated the wide correlation of the reduction in fat- free mass with the decrease in distribution volume and clearance of 5-fluorouracil [43]. Muscle tissue, in fact, in addition to acts in drugs' metabolism, is a large area of drugs' distribution, being richly vascularized. So, when there is a muscle reduction, an increase in drugs' plasma concentration occurs., This is usually associated with higher grade of toxicities [13].

A large part of our cohort is sarcopenic at diagnosis. This observation leads to consider that the main responsibles of muscle loss are tumor-related factors or pro-inflammatory cytokines, instead of chemotherapy related factors. Another hypotesis is that patients with diagnosis of breast cancer reduce their physical activity due to the decrease of the mood.

In line with literature data we found that sarcopenic status was significantly associated to higher risk of 

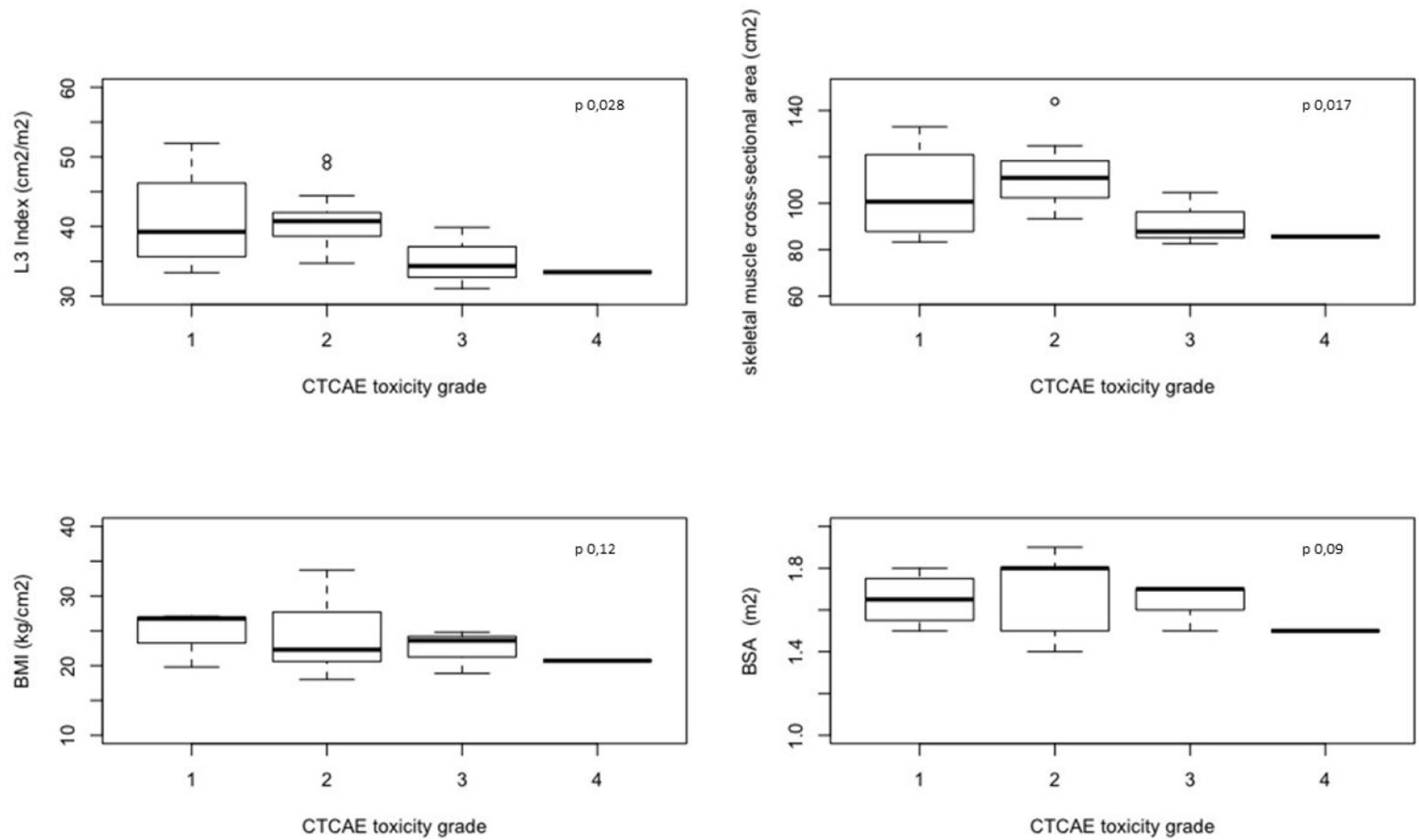

Figure 1: L3 Index, skeletal muscle cross-sectional area, BMI and BSA basal value in the 21 enrolled patients according to toxicity grade.

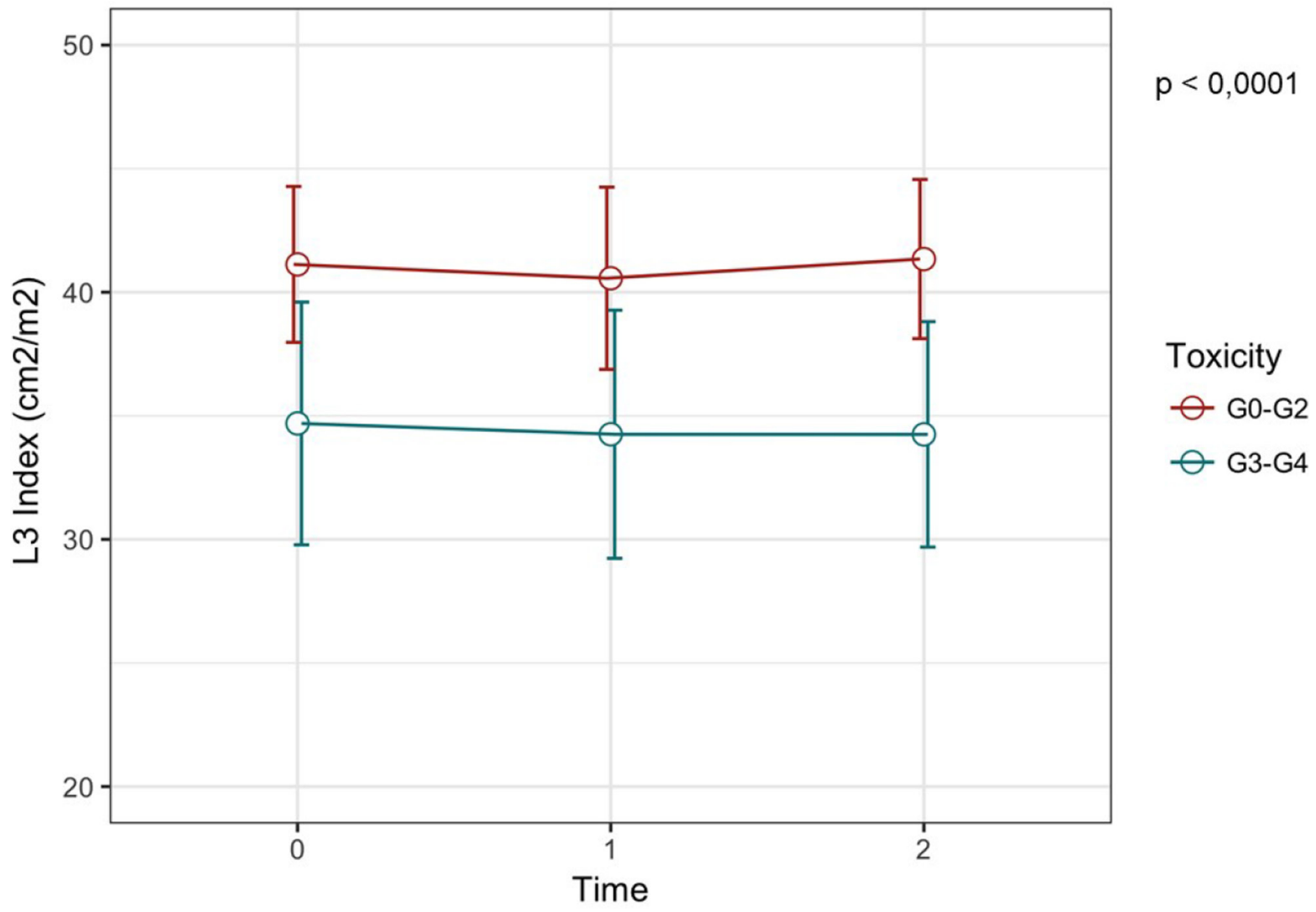

Figure 2: L3 Index variation over time according to toxicity grade. The red line show the L3 SMI at T0, T1 and T2 for the group of patients with G0-2 toxicities, while the blue line represent the variation of L3 SMI for patients with severe toxicities. We can observe that patients with G3-4 toxicities have a lower L3 SMI. 
developing toxicities. Moreover, we observes that treatment induces a raise in sarcopenia frequency in about $9.5 \%$ of the cases. This is probably due to the reduced food intake or to the reduced physical activity consequent to anticancer treatment.

Even though the small sample size and the retrospectivity of the analysis, these findings suggest the importance to consider body composition in determining drugs' doses. The prevention of LBM impairment could be useful to improve the quality of life of patients receiving chemotherapy.

During recent years, a growing interest in muscle mass maintenance in cancer patients has been observed. Most appetite stimulants or nutritional agents have been widely studied for prevention of cancer cachexia, leading to an increase in fat without an increase in lean body mass. Anabolic androgenic steroids showed more successful results in treating skeletal muscle wasting with an increased protein synthesis. The use of androgenic steroids is associated with several adverse events, such as hepatic toxicity, acne, increased sebum production, virilization and hirsutism in women. Moreover, there is a potential relation with prostate cancer and benign prostatic hyperplasia in men $[44,45]$. Selective androgen receptor modulators (SARMs) are currently studied. The advantages of this class of drugs is that they can selectively induce anabolism without the accompanying androgenic side effects. Dobs and colleagues showed, in a recently completed phase II trial, a significant increase in lean body mass in patients treated with enobosarm than in patients treated with placebo [46]. Moreover, two phase III trials of enobosarm to treat sarcopenia in metastatic NSCLC undergoing first line therapy have been recently completed (POWER trials; https://clinicaltrials.gov NCT01355484 and NCT01355497), showing a gain in lean body mass in the experimental arm [47].

In conclusion, our results support literature data showing a relation between sarcopenia and toxicity in cancer patients. In fact, sarcopenia is associated to worse outcome, to higher risk of complication after surgical intervention, to higher mortality and to the risk of developing severe toxicities $[5,13]$. In particular, adverse events are the major cause of dose reduction, delaying of administration and therapy discontinuation. Dose intensity loss avoidance has to be considered as a primary purpose of cancer treatment, above all in adjuvant setting. Furthermore, management of severe toxicities are a cause of health costs raise and quality of life impairment.

Future clinical trials investigating dose assessment based on LBM status, along with studies on sarcopenia prevention, have the potential to personalize treatment and to improve outcome and quality of life during chemotherapy.

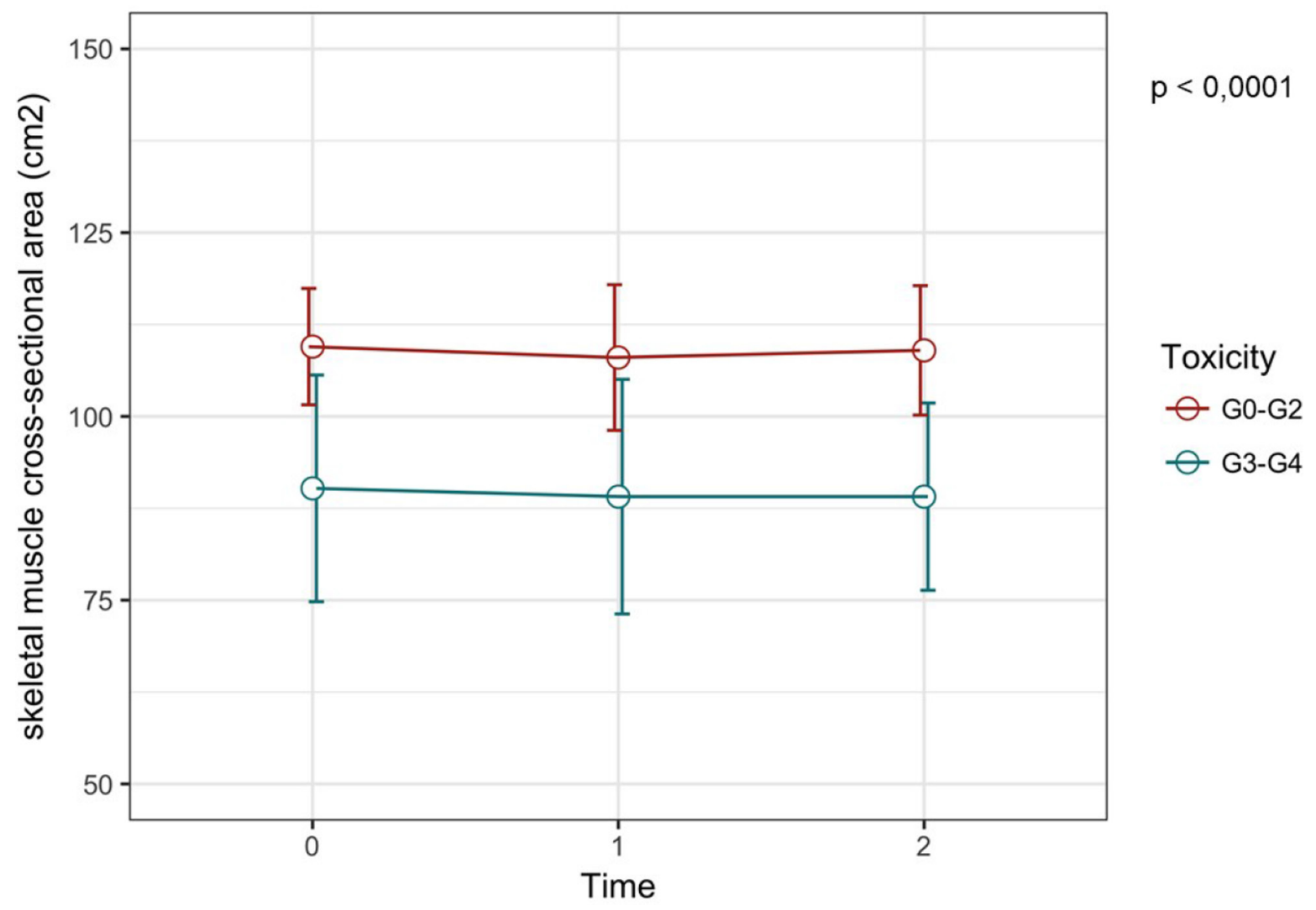

Figure 3: Skeletal muscle cross-sectional area variation according to toxicity grade. The red line show the skeletal muscle CSA at T0, T1 and T2 for the group of patients with G0-2 toxicities, while the blue line represent the variation of skeletal muscle CSA for patients with severe toxicities. We can observe that patients with G3-4 toxicities have a lower skeletal muscle CSA. 


\section{MATERIALS AND METHODS}

\section{Patients selection}

Stage I-III breast cancer patients who have received anthracycline-based adjuvant treatment at the Department of Medical Oncology, Sant'Andrea Hospital of Rome between February 2013 and April 2014 were retrospectively analysed.

The eligibility criteria was: histological diagnosis of early breast cancer, adjuvant anthracycline-based adjuvant chemotherapy received for at least 4 cycles, CT scan available before (Time $0, \mathrm{~T} 0$ ), during (Time 1, T1) and after (Time 2, T2) adjuvant chemotherapy.

BMI, BSA and toxicity according to the National Cancer Institute Common Toxicity Criteria (CTCAE) version 4.0 were assessed at each chemotherapy cycles.

The primary end-point of this study is to assess the association between sarcopenia, expressed as L3 SMI and skeletal muscle CSA, and toxicity in early breast cancer patient receiving adjuvant anthracycline. The secondary end-points are to assess the prevalence of sarcopenia in early breast cancer patients and to explore the variation of lean body mass during chemotherapy.

All the patients signed an informed consent. The study was conducted in accordance with the Declaration of Helsinki and the institutional ethic committee approved the protocols.

\section{Image analysis for sarcopenia}

Sarcopenia was evaluated by the analysis of available CT scan images performed before (T0), during (T1) and after (T2) adjuvant chemotherapy. A transverse section with a multiplanar reconstruction at L3 was used to study the following muscles: psoas, paraspinal, abdominal transverse rectum, internal and external obliques. Images were analysed by the software Slice Omatic V 5.0 (Montreal, Quebec, Canada Tomovision). The muscles areas were marked by the Hounsfield unit thresholds from -29 to +150 and the total CSA were computed. The CSA obtained in this way are normalized according to patients' height. Finally, the L3 SMI was calculated. According to previous published studies, sarcopenia was defined by a L3 SMI value $\leq 38.5 \mathrm{~cm}^{2} / \mathrm{m}^{2}$, because it is independent from BMI. Considering that obese or overweight patients could be sarcopenic, this cut-off is more useful to recognize sarcopenia, as showed by Prado and colleagues [11].

\section{Statistics}

The data were given as mean $\pm \mathrm{SD}$ or median (range) as appropriate. Boxplots of patient-related parameters over time were used to show variability among groups. Differences between groups were calculated by using a two-tailed $t$-test. Linear regression analyses were used to estimate correlations between toxicity-reported and patientrelated body composition data, carried-out before starting treatment, after the 2 th and 4 th cycle of chemotherapy. For the multivariate statistics, a stepwise forward multiple linear regression was performed. Differences were considered significant at $p$-value $<0.05$. All statistics were calculated using R-Package (version 3.3.2).

\section{Author contributions}

Mazzuca F: design of the study, protocol writing, manuscript revision; Onesti CE: data collection, manuscript writing; Roberto M: manuscript revision; Di Girolamo M: image analysis; Botticelli A: design of the study, protocol writing, data collection; Begini P: image analysis; Strigari L: statistical analysis; Marchetti P: design of the study; Muscaritoli M: design of the study, manuscript revision.

\section{CONFLICTS OF INTEREST}

The authors declare to have no conflicts of interest.

\section{FUNDING}

None.

\section{REFERENCES}

1. Evans WJ, Campbell WW. Sarcopenia and age-related changes in body composition and functional capacity. J Nutr. 1993; 123:465-468.

2. Cooper C, Fielding M, Visser M, van Loon LJ, Rolland Y, Orwoll E, Reid K, Boonen S, Dere W, Epstein S, Mitlak B, Tsouderos Y, Sayer AA, et al. Tools in the assessment of sarcopenia. Calcif Tissue Int. 2013; 93:201-210.

3. Fielding RA, Vellas B, Evans WJ, Bhasin S, Morley JE, Newman AB, Abellan van Kan G, Andrieu S, Bauer J, Breuille D, Cederholm T, Chandler J, De Meynard C, et al. Sarcopenia: an undiagnosed condition in older adults. Current consensus definition: prevalence, etiology, and consequences. International working group on sarcopenia. J Am Med Dir Assoc. 2011; 12:249-256.

4. Tsai S. Importance of lean body mass in the oncologic patient. Nutr Clin Pract. 2012; 27:593-598.

5. Muscaritoli A, Molfino A, Rossi Fanelli F. Muscle depletion and the prediction of chemotherapy toxicity. Intern Emerg Med. 2013; 8:373-375.

6. Mourtzakis M, Prado CM, Lieffers JR, Reiman T, McCargar LJ, Baracos VE. A practical and precise approach to quantification of body composition in cancer patients using computed tomography images acquired during routine care. Appl Physiol Nutr Metab. 2008; 33:997-1006. 
7. McLean RR, Kiel DP. Developing consensus criteria for sarcopenia: an update. J Bone Miner Res. 2015; 30:588-592.

8. Shen W, Punyanitya M, Wang Z, Gallagher D, St-Onge MP, Albu J, Heymsfield SB, Heshka S. Total body skeletal muscle and adipose tissue volumes: estimation from a single abdominal cross-sectional image. J Appl Physiol (1985). 2004; 17:2333-2338.

9. Binay Safer V, Safer U. Usefulness and limitations of single-slice computed tomography analysis at the third lumbar region in the assessment of sarcopenia. Crit Care. $2013 ; 17: 466$.

10. Gifford A, Walker RC, Towse TF, Brian Welch E. Correlations between quantitative fat-water magnetic resonance imaging and computed tomography in human subcutaneous white adipose tissue. J Med Imaging (Bellingham). 2015; 2:046001.

11. Prado CM, Lieffers JR, McCargar LJ, Reiman T, Sawyer MB, Martin L, Baracos VE. Prevalence and clinical implications of sarcopenic obesity in patients with solid tumours of the respiratory and gastrointestinal tracts: a population-based study. Lancet Oncol. 2008; 9:629-635.

12. Martin L, Birdsell L, Macdonald N, Reiman T, Clandinin MT, McCargar LJ, Murphy R, Ghosh S, Sawyer MB, Baracos VE. Cancer cachexia in the age of obesity: skeletal muscle depletion is a powerful prognostic factor, independent of body mass index. J Clin Oncol. 2013; 31:1539-1547.

13. Bozzetti F. Forcing the vicious circle: sarcopenia increases toxicity, decreases response to chemotherapy and worsens with chemotherapy. Ann Oncol. 2017; 28:2107-2118.

14. Cruz-Jentoft AJ, Baeyens JP, Bauer JM, Boirie Y, Cederholm T, Landi F, Martin FC, Michel JP, Rolland Y, Schneider SM, Topinková E, Vandewoude M, Zamboni M, et al. Sarcopenia: European consensus on definition and diagnosis: Report of the European Working Group on Sarcopenia in Older People. Age Ageing. 2010; 39:412-23.

15. Antoun S, Baracos VE, Birdsell L, Escudier B, Sawyer MB. Low body mass index and sarcopenia associated with dose-limiting toxicity of sorafenib in patients with renal cell carcinoma. Ann Oncol. 2010; 21:1594-1598.

16. Huillard O, Mir O, Peyromaure M, Tlemsani C, Giroux J, Boudou-Rouquette P, Ropert S, Delongchamps NB, Zerbib M, Goldwasser F. Sarcopenia and body mass index predict sunitinib-induced early dose-limiting toxicities in renal cancer patient. Br J Cancer. 2013; 108:1034-1041.

17. Arrieta O, De la Torre-Vallejo M, López-Macías D, Orta D, Turcott J, Macedo-Pérez EO, Sánchez-Lara K, RamírezTirado LA, Baracos VE. Nutritional status, body surface, and low lean body mass/body mass index are related to dose reduction and severe gastrointestinal toxicity induced by afatinib in patients with non-small cell lung cancer. Oncologist. 2015; 20:967-974.
18. Parson HA, Tsimberidou AM, Pontikos M, Fu S, Hong D, Wen S, Baracos VE, Kurzrock R. Evaluation of the clinical relevance of body composition parameters in patients with cancer metastatic to the liver treated with hepatic arterial infusion chemotherapy. Nutr Cancer. 2012; 64:206-217.

19. Prado CM, Baracos VE, McCargar LJ, Mourtzakis M, Mulder KE, Reiman T, Butts CA, Scarfe AG, Sawyer MB. Body composition as an independent determinant of 5-fluorouracil-based chemotherapy toxicity. Clin Cancer Res. 2007; 13:3264-68.

20. Ali R, Baracos VE, Sawyer MB, Bianchi L, Roberts S, Assenat E, Mollevi C, Senesse P. Lean body mass as an independent determinant of dose-limiting toxicity and neuropathy in patients with colon cancer treated with FOLFOX regimens. Cancer Med. 2016; 5:607-616.

21. Sjøblom B, Grønberg BH, Benth JŠ, Baracos VE, Fløtten $\varnothing$, Hjermstad MJ, Aass N, Jordhøy M. Low muscle mass is associated with chemotherapy-induced haematological toxicity in advanced non-small cell lung cancer. Lung Cancer. 2015; 90:85-91.

22. Tan BH, Brammer K, Randhawa N, Welch NT, Parsons SL, James EJ, Catton JA. Sarcopenia is associated with toxicity in patients undergoing neo-adjuvant chemotherapy for oesophago-gastric cancer. Eur J Surg Oncol. 2015; 41:333-338.

23. Tan BH, Birdsell LA, Martin L, Baracos VE, Fearon KC. Sarcopenia in an overweight or obese patient is an adverse prognostic factor in pancreatic cancer. Clin Cancer Res. 2009; 15:6973-6979.

24. Go SI, Park MJ, Song HN, Kim HG, Kang MH, Lee HR, Kim Y, Kim RB, Lee SI, Lee GW. Prognostic impact of sarcopenia in patients with diffuse large B-cell lymphoma treated with rituximab plus cyclophosphamide, doxorubicin, vincristine, and prednisone. J Cachexia Sarcopenia Muscle. 2016; 7:567-576.

25. Choi Y, Oh DY, Kim TY, Lee KH, Han SW, Im SA, Kim TY, Bang YJ. Skeletal Muscle Depletion Predicts the Prognosis of Patients with Advanced Pancreatic Cancer Undergoing Palliative Chemotherapy, Independent of Body Mass Index. PLoS One. 2015; 10:e0139749.

26. Stene GB, Helbostad JL, Amundsen T, Sørhaug S, Hjelde H, Kaasa S, Grønberg BH. Changes in skeletal muscle mass during palliative chemotherapy in patients with advanced lung cancer. Acta Oncol. 2015; 54:340-348.

27. Srdic D, Plestina S, Sverko-Peternac A, Nikolac N, Simundic AM, Samarzija M. Cancer cachexia, sarcopenia and biochemical markers in patients with advanced nonsmall cell lung cancer-chemotherapy toxicity and prognostic value. Support Care Cancer. 2016; 24:4495-4502.

28. Kumar A, Moynagh MR, Multinu F, Cliby WA, McGree ME, Weaver AL, Young PM, Bakkum-Gamez JN, Langstraat CL, Dowdy SC, Jatoi A, Mariani A. Muscle composition measured by $\mathrm{CT}$ scan is a measurable predictor 
of overall survival in advanced ovarian cancer. Gynecol Oncol. 2016; 142:311-316.

29. Ishihara H, Kondo $\mathrm{T}$, Omae $\mathrm{K}$, Takagi $\mathrm{T}$, Iizuka J, Kobayashi H, Tanabe K. Sarcopenia and the Modified Glasgow Prognostic Score are Significant Predictors of Survival Among Patients with Metastatic Renal Cell Carcinoma Who are Receiving First-Line Sunitinib Treatment. Target Oncol. 2016; 11:605-617.

30. Go SI, Park MJ, Song HN, Kang MH, Park HJ, Jeon KN, Kim SH, Kim MJ, Kang JH, Lee GW. Sarcopenia and inflammation are independent predictors of survival in male patients newly diagnosed with small cell lung cancer. Support Care Cancer. 2016; 24:2075-2084.

31. Kim EY, Kim YS, Park I, Ahn HK, Cho EK, Jeong YM. Prognostic Significance of CT-Determined Sarcopenia in Patients with Small-Cell Lung Cancer. J Thorac Oncol. 2015; 10:1795-1799.

32. Rutten IJ, van Dijk DP, Kruitwagen RF, Beets-Tan RG, Olde Damink SW, van Gorp T. The impact of sarcopenia and myosteatosis on outcomes of unresectable pancreatic cancer or distal cholangiocarcinoma. Clin Nutr. 2016; 35:1103-1109.

33. Prado CM, Baracos VE, McCargar LJ, Reiman $\mathrm{T}$, Mourtzakis M, Tonkin K, Mackey JR, Koski S, Pituskin E, Sawyer MB. Sarcopenia as a determinant of chemotherapy toxicity and time to tumor progression in metastatic breast cancer patients receiving capecitabine treatment. Clin Cancer Res. 2009; 15:2920-2926.

34. Prado CM, Lima ISF, Baracos VE, Bies RR, McCargar LJ, Reiman T, Mackey JR, Kuzma M, Damaraju VL, Sawyer MB. An exploratory study of body composition as a determinant of epirubicin pharmacokinetics and toxicity. Cancer Chemother Pharmacol. 2011; 67:93-101.

35. Shachar SS, Deal AM, Weinberg M, Nyrop KA, Williams GR, Nishijima TF, Benbow JM, Muss HB. Skeletal Muscle Measures as Predictors of Toxicity, Hospitalization, and Survival in Patients with Metastatic Breast Cancer Receiving Taxane-Based Chemotherapy. Clin Cancer Res 2017; 23:658-665.

36. Shachar SS, Deal AM, Weinberg M, Williams GR, Nyrop KA, Popuri K, Choi SK, Muss HB. Body Composition as a Predictor of Toxicity in Patients Receiving Anthracycline and Taxane-Based Chemotherapy for Early-Stage Breast Cancer. Clin Cancer Res 2017; 23:3537-3543.

37. Rier HN, Jager A, Sleijfer S, van Rosmalen J, Kock MC, Levin MD. Low muscle attenuation is a prognostic factor for survival in metastatic breast cancer patients treated with first line palliative chemotherapy. Breast 2017; 31:9-15.
38. Deluche E, Leobon S, Desport JC, Venat-Bouvet L, Usseglio J, Tubiana-Mathieu N. Impact of body composition on outcome in patients with early breast cancer. Support Care Cancer. 2018; 26:861-868.

39. Rutten IJ, van Dijk DP, Kruitwagen RF, Beets-Tan RG, Olde Damink SW, van Gorp T. Loss of skeletal muscle during neoadjuvant chemotherapy is related to decreased survival in ovarian cancer patients. J Cachexia Sarcopenia Muscle. 2016; 7:458-466.

40. Villaseñor A, Ballard-Barbash R, Baumgartner $\mathrm{K}$, Baumgartner R, Bernstein L, McTiernan A, Neuhouser ML. Prevalence and prognostic effect of sarcopenia in breast cancer survivors: the HEAL Study. J Cancer Surviv. 2012; 6:398-406.

41. Gyawali B, Shimokata T, Honda K, Kondoh C, Hayashi N, Yoshino Y, Sassa N, Nakano Y, Gotoh M, Ando Y. Muscle wasting associated with long term use of mTOR inhibitors. Mol Clin Oncol. 2016; 5:641-646.

42. Sawyer M, Ratain MJ. Body surface area as a determinant of pharmacokinetics and drug dosing. Invest New Drugs. 2001; 19:171-177.

43. Gusella M, Toso S, Ferrazzi M, Padrini R. Relationship between body composition parameters and fluorouracil pharmacokinetics. Br J Clin Pharmacol 2002; 54:131-139.

44. Basaria S, Wahlstrom JT, Dobs AS. Clinical review 138: anabolicandrogenic steroid therapy in the treatment of chronic diseases. J Clin Endocrinol Metab. 2001; 86:5108-5117.

45. Lesser GJ, Case D, Ottery F, McQuellon R, Choksi JK, Sanders G, Rosdhal R, Shaw EG. A phase III randomized study comparing the effects of oxandrolone (Ox) and megestrol acetate (Meg) on lean body mass (LBM), weight (wt) and quality of life (QOL) inpatients withsolid tumors and weight loss receiving chemotherapy. J Clin Oncol. 2008; 26:9513.

46. Dobs AS, Boccia RV, Croot CC, Gabrail NY, Dalton JT, Hancock ML, Johnston MA, Steiner MS. Effects of enobosarm on muscle wasting and physical function in patients with cancer: a double-blind, randomised controlled phase 2 trial. Lancet Oncol. 2013; 14:335-345.

47. Crawford J, Prado CM, Johnston MA, Gralla RJ, Taylor RP, Hancock ML, Dalton JT. Study Design and Rationale for the Phase 3 Clinical Development Program of Enobosarm, a Selective Androgen Receptor Modulator, for the Prevention and Treatment of Muscle Wasting in Cancer Patients (POWER Trials). Curr Oncol Rep. 2016; 18:37. 